\title{
RAÍZES TEÓRICAS DA INSERÇÃO DA EMPATIA NA TEORIA ECONÔMICA
}

\author{
Vitória Saraiva de S. Gomes.
}

\begin{abstract}
Resumo
O objetivo do trabalho é explorar os possíveis efeitos da empatia e, conjuntamente, do altruísmo nas tomadas de decisões proferidas pelos agentes do mercado. Para isso, buscamos as raízes teóricas e analisamos algumas das diferentes abordagens quanto aos conceitos de empatia e altruísmo, se é possível ou não modificar as decisões dos agentes por meio da indução dos mesmos e se eles impactam de forma mais ou menos intensa agentes com diferentes características.
\end{abstract}

Palavras-chave:

Empatia, altruísmo, economia comportamental.

\section{Introdução}

A economia comportamental é a combinação entre economia e psicologia que estuda os mercados nos quais os agentes apresentam limitações humanas e complicações no geral (Mullainathan e Thaler, 2000). Essa área começa a ganhar destaque a partir da segunda metade do século XX. Foram identificadas lacunas na teoria microeconômica clássica quanto à tomada de decisões dos indivíduos e percebeu-se a necessidade de ir além. Desde seus primeiros teóricos, a economia comportamental se mostra cada vez mais útil na compreensão de como e porque os agentes agem, para além da idealização do homus economicus. A neurociência tem auxiliado de forma extensiva, com o estudos combinados das duas áreas, em especial quanto à influência e efeitos da empatia e do altruísmo nos seres humanos. Esses dois conceitos são alvo de diversos estudos e debates, pela centralidade que têm no processo de tomada de decisão diária, visto que os seres humanos são seres não apenas egocêntricos, mas sociais.

O objetivo do presente trabalho é explorar os possíveis efeitos desses dois conceitos para a tomada de decisão dos agentes e a intensidade desses efeitos nos agentes com características distintas e em diferentes situações.

\section{Resultados e Discussão}

Já em 1955, Herbert Simon discutia a insuficiência da teoria microeconômica clássica e do conceito de homus economicus estritamente racional e objetiva para a análise do processo de tomada de decisão. Nada nunca comprovou que um indivíduo fosse capaz de fazer todas as análises quanto a todos os detalhes relacionados ao objeto de decisão a priori. Os seres humanos apresentam limitações de capacidade cerebral e tempo, diversas vezes as pessoas simplesmente adotam regras de ouro para economizar esforços cognitivos.

A teoria prospectiva é uma teoria, dentro da economia comportamental, que descreve como as pessoas tomam decisões em contextos de incerteza. Os seres humanos, mesmo sabendo o que é melhor, às vezes falham em suas decisões por motivos como de autocontrole (Mullainathan e Thaler, 2000).

A teoria metaeconômica, colocada por Gary Lynne, propõe que os seres humanos não tomam decisões por interesses puramente individuais e racionais, mas também há uma tendência de estarem submetidas a sentimentos subjetivos. A maior parte dos indivíduos estão constantemente em conflito quanto aos interesses individuais e coletivos e a escolha racional envolve estar ciente de ambos os interesses. A necessidade de se sentir parte de algo maior, ocorre por meio do processo de empatia, definida pelo autor como a capacidade de se imaginar no lugar do outro em uma situação em específico.

Daniel Batson e Tecia Moran colocam o conceito de empatia como a resposta emocional orientada ao outro, congruente com a percepção de bem-estar do outro e se ele está em necessidade. Para os autores, o altruísmo, definido como uma forma distinta de motivação pró-social, não uma motivação moral, pode ser motivado por meio da empatia e isso pode alterar o processo de tomada de decisão dos indivíduos. Porém, nem todos os autores tratam da empatia a partir da mesma definição.

A partir de um estudo neurocientífico, Tania Singer elucida a diferença entre mentalização e empatia, que seria a capacidade de compartilhar sentimentos com outros. As duas capacidades por ela definidas despertam partes distintas do cérebro como visto em alguns estudos, o que é um importante avanço para as análises nos processos de tomada de decisão.

\section{Conclusões}

A empatia e o altruísmo apresentam um papel central na tomada de decisão dos agentes dentro da economia, visto que que os seres humanos são seres sociais e apresentam uma grande necessidade de se sentir pertencentes a um grupo. A área de economia comportamental, em conjunto com a neurociência tem estudado cada vez mais essa quesão e comprovado a sua centralidade, nos permitindo explorar de forma cada vez mais realista o processo de tomada de decisão.

\section{Agradecimentos}

Agradeço ao programa Cnpq/PIBIC pelo financiamento da pesquisa e ao meu orientador Gustavo Aggio por todo 0 apoio.

\footnotetext{
${ }^{1}$ Batson, D. e Moran, T. European Journal of Social Psychology 29, 909-924, 1999

2 Thaler, R. e Mullainathan, S. Nber Working Paper Series 7948, 2000

${ }^{3}$ Lynne, G. The Journal of Socio-Economics 35, 634-651, 2006.

${ }^{4}$ Kirman, Alan e Teschl, M. Philosophical transactions of the Royal Society 365 , 303-317, 2010.

5 Simon, H. The MIT Press, 1955

${ }^{6}$ Singer, T. Neuroscience and Biobehavioral Reviews 30, 855-863, 2006.

${ }^{7}$ Christov-Moore, L.; Simpson, E.A.; Coudé, G.; Grigaityte, K.; Iacoboni, M. e Ferrari, P.F. Neuroscience and Biobehavioral Reviews, 604-627, 2014.

${ }^{8}$ Ferrari, P.F. NIH Public Access, 297-313, 2014.
} 